\title{
The Impact of Physical Appearance on Employment Competitiveness
}

\author{
Shihui Pan \\ Guangdong Experimental High School, Guangdong, 510375, China \\ Email:panshihui62@gmail.com

\begin{abstract}
Physical appearance is a criterion for determining a person's level of appearance. Being attractive is a social concern that affects everyone's life, including mate choice, social interaction, confidence, and happiness, etc. However, a growing number of data surveys point out that physical appearance has a significant impact on job competition. This research mainly focuses on how much one's attractiveness affects employment and whether it would influence other factors, such as interpersonal communication and professional skills. The finding reveals that appearance plays an indispensable role in job competitiveness and sometimes determines whether or not an applicant is hired. In conclusion, appearance has become an inevitable competitive advantage.
\end{abstract}

Keywords: Physical attractiveness, Employment competitiveness, Professional skill, Communication skill

\section{INTRODUCTION}

Yanzhi, a Chinese cyber term, refers to the aesthetic worth of one's appearance. Its function is to evaluate the level of beauty of human faces and rate their attractiveness [1]. This phrase can be substituted for "physical attractiveness" in terms of psychology. Individuals who are attractive can be identified by their facial symmetry, facial features, and body shape. Employment competitiveness refers to the abilities and skills that employees possess that are required and deemed desirable by the labor market and employers, and that provide employees with a relative competitive edge in the labor market (Howard, 1995; Liu Hui, 2009).

Physical appearance has recently been a contentious issue, influencing every aspect of people's life. The attractiveness-induced halo effect has been proved in the workplace, specifically in relation to recruiting choices and employee potential assessment [2]. A vast majority of businesses would prefer to recruit individuals who have a more appealing appearance. Those people are considered more capable by employers. Numerous scholars have offered pertinent perspectives and ideas on the relationship between physical attractiveness and employment. According to Muwen W. and Erpo L., employers favor candidates who have facial attractiveness [3]. Hamermesh and Biddle suggest that not only in job hunting but also at employment, people with gorgeous and handsome faces are more likely to get a raise [4]. Apparently, this following situation displays great unfairness to those with an ordinary face. The primary objective of this paper is to discover the significance of facial appearance in employment competitiveness. First, while interviewing multiple employees in the same competency, would the employer make a selection solely based on the employees' looks, or would the employers propose other questions to evaluate? Second, would employers still prefer the applicant with an outstanding look if there is a large disparity in his or her ability? For instance, those with ordinary appearances are competent, whereas those with outstanding appearances have the lower ability. Finally, how many people have lost job opportunities due to their appearance?

Attractiveness could be achieved not only by physical appearance but also through the development of personal strength and some abilities. In society, numerous people advocate the thought that being beautiful is almighty. It is true that everyone admires every appealing object, but, on the other hand, it displays great unfairness as well. Individuals must adapt to the ever-changing world. If they want to obtain occupation or be promoted to a higher position, being physically attractive is insufficient. This paper would primarily focus on the weight of physical appearance in the process of employment competitiveness. 


\section{LITERATURE REVIEW}

\subsection{What Physical Appearance Can Bring For People}

In China, an old proverb says, "It is in every person's nature to appreciate the beauty," and according to the concept of physical attractiveness, individuals appear to prefer approaching those with gorgeous faces. Despite the fact that many people emphasize that uncovering the hidden intent is difficult, a beautiful face is essential if people want to be thoroughly understood by others [5]. Those with a striking appearance are often thought to be more capable, friendlier, and more trustworthy. When people have interactions with each other, the first and only piece of information available to others is appearance, which could have strong effects on others' behaviors [6]. In this scenario, attractive people have a considerable advantage when it comes to displaying the first impression to employers.

Various industries have varying standards for people's appearance. Employers in the service industry, such as automobile models and flight attendants, have stricter appearance criteria [7]. According to the report of 2018 China Youth Appearance Competitiveness, the physical appearance of employees is the most significant requirement. Furthermore, $70.6 \%$ of the recruiters from the service sector hold the point that physical appearance would be measured by different industries and positions. Becker states that interviewers would occasionally choose an employee based on their personal preferences, disregarding his or her abilities. As a result, individuals with ordinary appearances would have a lower employment rate [8]. In addition, people have demonstrated stereotypes about the idea that being beautiful is beneficial in practically every aspect which has been implanted in them from infancy. Some academics indicate that people with beautiful or handsome faces will work more successfully [9]. Several studies in recent years claim that "Today is an era of remarkable attention to physical appearance". According to Yaping G., physical appearance is regarded by an increasing number of groups as a critical component of labor market competitiveness [10]. Because of the growing demands for employees' appearance, job pressure and competition are substantially higher and cruel. People with less physical attractiveness are more likely to be sifted out. Under this circumstance, the amount of people seeking plastic surgery is increasing at an alarming rate. In summary, appearance, obviously, has unavoidable impacts on employment competitiveness. Additionally, the success rate of employment of those who have outstanding looks will be definitely higher than those with ordinary looks.

\subsection{Factors That Affect Employment Competitiveness}

\subsubsection{Interpersonal Communication}

Interpersonal communication ability refers to an individual's capacity for effective communication with others, which includes both exterior skills and internal motivation [11]. Wang Xin concretizes this notion that individuals can effectively and clearly transmit their thoughts and attitudes to others within a certain time frame and can swiftly extract useful information from others' feedbacks [12]. According to employers from diverse organizations, communication skills are the most critical of a candidate's competencies and have gradually become the cornerstone of personal success. Bi Tingyan pointed out that this ability is not innate and must be learned from experience [13]. People's careers will benefit considerably by mastering communication skills, which are undoubtedly demanded by companies and industries. As a result, possessing excellent communication skills is extremely essential. Ma Xiangtao proposes that the communication skills courses should be integrated into the college training curriculum system, with an emphasis on promoting awareness of the importance of communication skills, in order for graduates to excel in the employment competition and raise their employment success rate [14]. According to $\mathrm{Li}$ Jundeng (2008), schools should strengthen their language expression teaching so that more and more students are able to engage effectively with others.

\subsubsection{Professional Skills And Work Experience}

Professional skills, a prerequisite for recruitment, are a critical factor for determining if an applicant's personal capacity matches the company's requirements. Work experience refers to the cumulative amount of time that someone has worked. It indicates the level that someone is at, which firms will normally hire someone with prior expertise in that sector of work to save on training expenditures (Liu Chang, 2019). Marketers, for example, must be capable of evaluating and planning, which necessitates the ability to perform independent market research, devise planning schemes, and be knowledgeable about sales and strategies. Along with acquiring knowledge, personnel must possess broad experience of participating in a variety of marketing activities [15]. In the 2016 China Internet Hottest Jobs Talent Report, R\&D engineers (Research and Design Engineer) and data analysts are the most in-demand talent positions in the industry. The demand for $\mathrm{R} \& \mathrm{D}$ engineers is the highest, while data analysis talents are the scarcest. Data-related jobs have exceptionally high professional skill requirements, demanding in-depth analysis of data, text, and knowledge of computer networks and technology. This kind of position needs one to three years of work experience, as it is primarily 
concerned with applicants' professional understanding of the practical procedures associated with their subject field [16].

\subsection{The Relationships Between Physical Appearance And Some Skills (Interpersonal Communication Skill, And Professional Skill And Work Experience)}

It is apparent that physical appearance would influence one's life, particularly in the workplace. Nowadays, there is a popular and humorous saying on the Chinese Internet that individuals may earn money based on their physical appearance but always rely on their talent, which is a compliment to a person's ability and talent as well as his or her attractive face [17]. It can be imagined that how advantageous it would be with good-looking faces in job competition. Kuhn and Shen calculate that 24.3 percent of recruitment enterprises would place a premium on applicants' appearance if the ability and educational background of applicants is insufficient. However, employers would be more favorable to hire someone who possesses both, indicating that an appealing face would somehow help people be more accessible to seek a job [18]. This demonstrates a negative correlation between physical appearance and the possession of skill and ability.

To summarize, physical beauty has a beneficial effect on job competitiveness as people like to beautify the attractive one for the reason that they consider that what is beautiful is always good. Nevertheless, interpersonal communication skills, professional skills, and experience should not be neglected in the interest of demonstrating people's hard power.

\section{METHOD}

This research solely conducts a survey as the experiment. The questionnaire was randomly assigned to 200 people aged 16 to 50. Among them, 191 questionnaires are valid. Up to $86.5 \%$ of respondents believe that physical appearance could greatly influence employment competitiveness. Over half of respondents claim that people who are facially attractive are more likely to form social relationships and have a higher employment success rate. Approximately $60 \%$ of respondents claim that they are influenced by their physical appearance both at school and in the workplace. Besides, there is a question that shows two pictures of employees - one is young and attractive, whereas the other is older and ordinary. Nearly two-thirds of people choose the younger one. However, when additional considerations are included, a portion of people - approximately 170 - asserts that companies should recruit employees based on their qualities, particularly communication ability and professional skill, not their appearance. To be specific, 125 people consider professional skill is more important and 50 people prefer those with superior communication ability. Apart from this, $59.5 \%$ of respondents state that employers should minimize inequity by avoiding recruiting employees who are physically appealing but lack competence. Instead, they should emphatically cultivate those who are potential and capable.

\section{CONCLUSION}

Overall, the foregoing findings indicate that physical appearance affects employment competitiveness to a large degree, although it is not the most essential factor. First and foremost, there is no denying that many people's lives are influenced by their physical appearance, such as being treated unjustly at school or in working environments. Second, it is unquestionable that when people with attractive appearances are exposed to the job-hunting process, their employment success rate would be higher. Unfortunately, a tiny percentage of candidates are rejected during the interview process due to their physical appearance. However, in reality, when numerous candidates demonstrate the same level of competence during the interview, employers would perform additional tests to evaluate which candidate is the greatest match. Moreover, even if an applicant's looks are less appealing, employers would still choose the qualified one. They are quite clear that an attractive face is incapable of doing any task.

As more people feel unfair in employment competition, they are considering plastic surgery to improve their physical attractiveness and make themselves more outstanding in appearance. In fact, staffs in senior management are distinct that employees should be evaluated based on their ability to perform tasks that companies require and demand, as well as the attitude of being enterprise and responsible. Everyone should be treated equally. Employers should treat all employees with respect- the stronger should be kept. Besides, nowadays, inner beauty gradually becomes an essential consideration in the job-seeking process. The significance of this paper is to appeal to people that although physical appearance would facilitate one's life, potential and comprehensive abilities would still be regarded as the "hard power". What companies truly require are those who could maintain their job regardless of how harsh or challenging it is. Moreover, physical beauty could be the shining point, but inner beauty authentically determines whether or not a person is the qualified one at any time. Future studies would mainly explore this issue further based on the influence of physical appearance on social events.

\section{REFERENCES}

[1] Jing, M. (2016) The Explanation of Cyber Word "Physical Appearance in Cognitive Linguistics. 
China Academic Journal Electronic Publishing House, 127-130.

[2] Heilman M.E. and Stopeck M.H. (1985) Being Attractive, Advantage or Disadvantage? Performance Based Evaluations and Recommended Personnel Actions as a Function of Appearance, Sex, and Job Type. Organizational Behavior and Human Decision Process. 35: 202-215.

[3] Wang, M. W., Lu, E. P. (2018) Are People Who Have More Beautiful Faces More Easily To Find A Job. China Economic Studies, 5:111-124.

[4] Hamermesh D. S. and J. E. Biddle, 1998, "Productivity and Discrimination: Lawyers' Looks and Lucre," Journal of Labor Economics, 16(1): 172-201.

[5] Guan J. (2020) The Interpretation of the Phenomenon of Beauty Worship from the Perspective of Social Psychology. China Academic Journal Electronic Publishing House.

[6] Neumann L.P., Vazure S., Rentfrow P.J., and Gosling S.D. (2009) Personality Judgements Based on Physical Appearance. The Society for Personality and Social Psychology. DOI: $10.1177 / 0146167209346309$.

[7] Tan Y. F., Fu X. S. (2018) Physical Appearance VS Ability: Research on the Factors That Influence Employment Opportunities of Master of Finance Major [J]. Monthly Journal of Education, 10: 87-95.

[8] Becker, G. S. (1971) The Economics of Discrimination. Chicago: The University of Chicago Press.

[9] Toledano E. (2013) May The Best (Looking) Man Win: The Unconscious Role of Attractiveness in
Employment Decisions. Cornell HR Review.

[10] Guo Y. P. (2020) The Impact of Physical appearance on Non-cognitive Ability. China Academic Journal Electronic Publishing House, 1: 36-46. DOI: 10.13583/j.cnki.issn1004-3780.2020.01.004.

[11] McKay M., Davis M., Fanning P. (2003) Communication Skills. Leads Press.

[12] Wang X. (2014) The Research on the Relationship Between College Students Interpersonal Communication Ability and Employment Interview Ability. China Academic Journal Electronic Publishing House.

[13] Bi T. Y. (2012) Research on Promotional Problem of Interpersonal Communication Ability. 2012 Conference on Psychology and Social Harmony.

[14] Ma X. T. (2009) Investigation on College Students' Interpersonal Communication Ability. Chinese Master's Theses Full-text Database.

[15] Cao Y., Wang Q. W., Xie L. L. (2014) Research on the Demand of College Students' Recruitment and Interview Ability. China Academic Journal Electronic Publishing House. DOI: 10.16517/j.cnki.cn12-1034/f.2014.04.023.

[16] Zhang J. F., Wei R. B. (2018) Data Post Talent Demand Characteristics Mining of Domestic Recruitment Websites. Journal of Intelligence, 37(6): 176-182.

[17] Wang S. G. (2018) Does Physical Appearance Affect Income, China Academic Journal Electronic Publishing House, 39(4): 19-33.

[18] Kuhn P., Shen K. (2013) Gender Discrimination in Job Ads: Evidence from China [J]. Quarterly Journal of Economics, 128(1): 287-336. 